\title{
Experimental observations of an installed-on-pylon contra-rotating open rotor with equal blade number in pusher and tractor configuration
}

International Journal of Aeroacoustics 2016, Vol. I5(I-2) 228-249

(C) The Author(s) 2016

Reprints and permissions:

sagepub.co.uk/journalsPermissions.nav DOI: $10.1177 / \mid 475472 \times 16642063$ jae.sagepub.com

(9SAGE

\author{
Petr Eret,' John Kennedy,' Francesco Amoroso, ${ }^{2}$ \\ Paolo Castellini ${ }^{3}$ and Gareth J Bennett ${ }^{\prime}$
}

\begin{abstract}
Noise from contra-rotating open rotors is a major obstacle to the adoption of this fuel efficient technology as a viable aircraft propulsion system. A better understanding of both contra-rotating open rotor noise generation and reduction has been achieved due to ongoing extensive research. One of the most recent research activities is the WENEMOR (wind tunnel tests for the evaluation of the installation effects of Noise EMissions of an open rotor advanced regional aircraft) project, which has been developed in response to the requirements described in the Clean SkyIntegrated Technology Demonstrators under the heading of Green Regional Aircraft. The project investigates the airframe installation effects of a $1 / 7$ th scale model of a regional aircraft equipped with two contra-rotating open rotors of the same rotor diameter, the same rotational speed and equal blade number. For this case, the blade passing frequency of rotor-alone tones and the frequency of relevant interaction tones cannot be distinguished due to the equal blade count of the two rotors. This study presents the tone directivity plots up to $4 \times$ blade passing frequency of the isolated WENEMOR single pylon contra-rotating open rotor engine in both pusher and tractor configurations at various angles of incidence and flow velocities. A linear array of I 3 microphones is deployed for the far field sound measurements. The tone directivity trends show the efficient on-axis acoustic radiation at all blade passing frequency tones with the contra-rotating open rotor tone at $2 \times$ blade passing frequency dominating in the vast majority of the tests. The main objective is to compare the acoustic emission of pusher and tractor configurations tested under the same flow velocities and angles of incidence. The results suggest that the pusher
\end{abstract}

\footnotetext{
'School of Engineering, Trinity College Dublin, Ireland

${ }^{2}$ Eurotech, Italy

${ }^{3}$ Department of Industrial Engineering and Mathematical Sciences, Universita Politecnica delle Marche, Italy

Corresponding author:

Gareth J Bennett, School of Engineering, Trinity College Dublin, Dublin D02 PN40 Ireland.

Email: bennettg@tcd.ie
} 
configuration of the isolated contra-rotating open rotor tends to be slightly louder than the tractor at $2 \times$ blade passing frequency. However, it is shown that the acoustic performance of the isolated contra-rotating open rotor is complicated and sensitive to any change in the flow velocity and the angle of incidence. The increasing flow velocity and the increasing angle of incidence show limited consistency in proportional trends in the directivity plots of sound pressure levels. It is anticipated that the findings will be different for a more realistic case of installedon-model contra-rotating open rotor.

\section{Keywords}

Contra-rotating open rotor, equal blade number, single pylon, tractor and pusher configuration, open jet wind tunnel, acoustic measurements

Date received: 9 December 20I4; revised: 22 April 20I5; accepted: 6 May 2015

\section{Introduction}

There is a considerable interest at present in both the EU and the US on the implementation of new "open rotor" propulsion systems, which could achieve significant energy savings in respect of reduced fuel consumption and potentially lower emissions. Earlier efforts, which culminated in flight tests of a contra-rotating open rotor (CROR) on modified Boeing 727 and McDonnell Douglas MD-80 airframes, were discontinued in the 1980s primarily as a result of falling oil prices. However, since then, increasing fuel costs and broader environmental constraints oblige the industry to rejuvenate its consideration of open rotors. The Fundamental Aeronautics Program of NASAs Aeronautics Research Mission Directorate have begun to fund GE and Boeing for test programs on both isolated open rotor propulsion systems and on scale models of aircraft equipped with these propulsion systems in low-speed wind tunnels to simulate low-altitude aircraft for acoustic evaluation. In Europe, activity can be found, for example, in the Clean Sky Joint Technology Initiative, which is a PublicPrivate Partnership between the European Commission and Industry implementing the Level 3 project approach (closer to the market research, based on demonstrators of high technology readiness levels) of FP7 (Framework Program 7).

One of the primary concerns in developing a viable design is the noise impact of CROR, especially at take-off/approach. Although broadband noise can be significant for some flight conditions, as shown by Blandeau et al., ${ }^{1}$ tonal noise generally remains the major component. At cruise, the key noise source is rather of quadrupolar nature, due to the flow compressibility and the shocks that occur because of the tip relative trans-sonic Mach numbers, and the rotor-alone tones dominate the CROR spectrum. At low-speed conditions, rotor-rotor interaction noise due to aerodynamic interference, contributes significantly to the noise signature. The mechanisms responsible for the CROR interaction noise can be attributed to the following flow features: (i) rear-rotor upstream influence interacting with the front rotor, (ii) tip-vortices shed from the front rotor interfering with the rear rotor, (iii) front-rotor viscous wakes affecting the rear-rotor loading, and (iv) front-rotor hub wake and hub boundary layer influencing the rear-rotor hub loading. Peters and Spakovszky ${ }^{2}$ have decomposed and quantified the individual underlying noise mechanisms in combined computational fluid dynamics (CFD) and computational aeroacoustic analysis (CAA). They developed a quieter CROR design, which incorporates a clipped rear-rotor and increased 
rotor-rotor spacing to reduce upstream influence, tip-vortex, and wake interaction effects. The design also introduced (i) a higher blade count of the rear rotor than the front rotor in order to limit the loading increase on the rear rotor while maintaining thrust, and (ii) reduction of the rear-rotor tip speed, which requires a modification of the planetary gearbox carrier. This advanced CROR design is more suitable for a tractor configuration as the carrier driven rotor must be located furthest away from the engine core. Zachariadis et al. ${ }^{3}$ have suggested that by repitching the front rotor and increasing its rotational speed during take-off, the noise from open rotors can be significantly reduced across all directivities. Moreover, there is also scope for overall CROR geometry (including blade shape) optimization for maximizing the propeller efficiency at the top of climb and minimizing the interaction noise at take-off conditions as shown by Schnell et al. ${ }^{4}$

Despite the use of modern advanced theoretical and numerical development tools, experimental work is still essential and necessary. Several extensive campaigns were performed in recent years, for example Ricouard et al.; ${ }^{5}$ Elliott; ${ }^{6}$ Czech and Thomas; ${ }^{7}$ Zante; ${ }^{8}$ Stephens and Envia; ${ }^{9}$ Fernando and Leroux. ${ }^{10}$ The wind tunnel tests for the evaluation of the installation effects of Noise EMissions of an open rotor advanced regional aircraft (WENEMOR) test campaign, Bennett et al., ${ }^{11}$ was conducted as a response to a Clean Sky call for proposals under SP1-JTI-CLEAN SKY-2010-4 entitled "Aero-acoustic noise emissions measure for advanced Regional Open Rotor A/C configuration" and forms part of the Clean SkyIntegrated Technology Demonstrators under the heading of Green Regional Aircraft (GRA) of which Alenia Aermacchi, Italy and EADS CASA, Spain are the leaders. The project consortium consisted of seven partners including two universities (Trinity College Dublin and Universita Politecnica delle Marche), a large European wind tunnel facility (Pininfarina) and several small or medium enterprises (SMEs) (Eurotech, Teknosud, MicrodB and Paragon S.A.) with specific competencies in design, manufacture, noise measurements, and data analysis, see Table 1.

WENEMOR addressed the topic by carrying out aero-acoustic measurements in the open test section of a large low-speed wind tunnel using a complete modular reduced scale model of different configurations of an aircraft with installed open rotor systems operating in both pusher and tractor modes. The principal goal of the project was to assess experimentally the noise shielding effectiveness of classic airframe components for different Open Rotor aircraft configurations. A complete 1/7th scaled aircraft was designed and built for installation in the Pininfarina Aerodynamic and Aeroacoustic Research Center Wind Tunnel. The model had two Open Rotors with contra-rotating fans at the same scale as the airframe. Various

Table I. WENEMOR partners.

\begin{tabular}{ll}
\hline Partner & Country \\
\hline Trinity College Dublin (Coordinator) & Ireland \\
Universita Politecnica delle Marche & Italy \\
Paragon & Greece \\
Eurotech SAS & Italy \\
MICRO DB SA & France \\
Teknosud S.R.L & Italy \\
Pininfarina SPA & Italy \\
\hline
\end{tabular}


positions of the open rotors with respect to the airframe were tested with noise measurements being performed at both near and far field locations. The test campaign provided, for the first time in Europe, a comprehensive database on noise installation effects for novel regional advanced aircraft concepts using OR propulsion systems.

The project investigates the airframe installation effects of a $1 / 7$ th scale model of regional aircraft equipped with two CRORs of the same rotor diameter and equal blade number. Some authors, such as Parry and Vianello ${ }^{12}$ have deliberately excluded equal blade number configurations from further analyses, because such designs generate zero (or plane wave) modal sound fields that radiate high on-axis noise levels. However, the GRA community planned to test acoustically the equal blade number setup with WENEMOR advanced nacelle and blade profiles (details are confidential).

This paper presents the noise directivity trends of the WENEMOR single pylon CROR engine of equal blade number configuration without any airframe influence. Effects of various angles of incidence and flow velocities on pusher and tractor configurations are investigated. The main objective is to compare the acoustic emission of pusher and tractor configurations tested at the same flow velocities and angles of incidence. In addition to the noise characteristics, the results are intended to serve as a database for the validation of numerical codes. Some preliminary achievements with a satisfactory agreement between the numerical and experimental data can be found in Sanders et al. ${ }^{13}$

\section{Experimental facilities and instrumentation}

The test program was conducted at The Pininfarina Aerodynamic and Aeroacoustic Research Center in Turin, Italy. The semi-cylindrical open jet wind tunnel collector of radius $3 \mathrm{~m}$ and a test section of $8 \mathrm{~m} \times 9.6 \mathrm{~m} \times 4.2 \mathrm{~m}$ are shown in Figure 1. Figure 2 depicts the out-of-flow microphone used for background measurements in an empty wind tunnel (engine running without blades installed was not tested). The background noise level

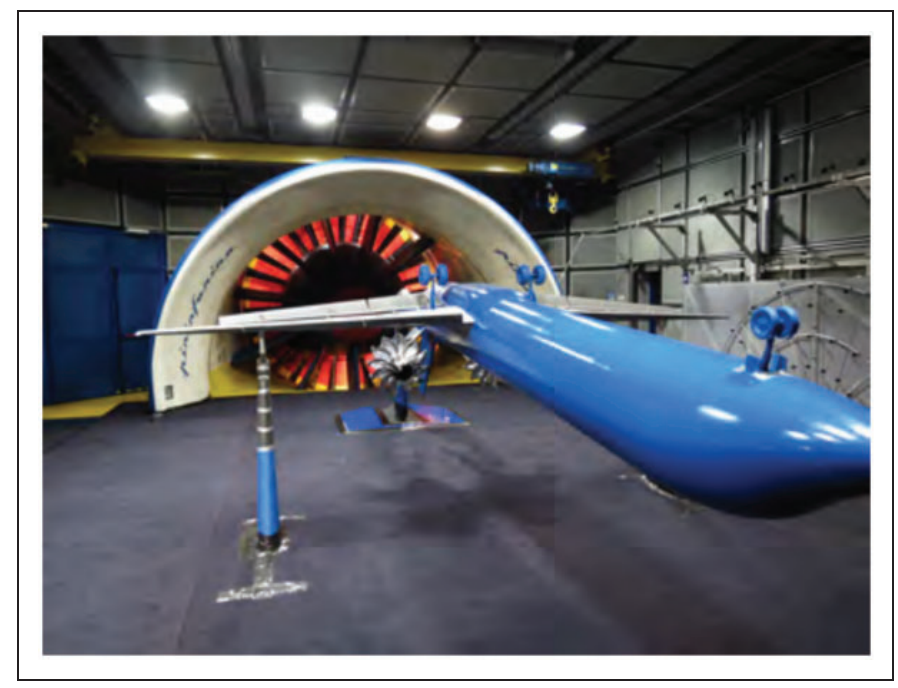

Figure I. Pininfarina wind tunnel facility with full model installed. 
measured was found to be $10 \mathrm{~dB}$ lower than the tonal noise sources under investigation in this work which was considered to be satisfactory. The tunnel produces a uniform velocity flow, which varies by only $0.5 \%$ over the area of the test section with a turbulence intensity, which can be controlled between $0.26-8 \%$ as the tunnel also contains a controllable turbulence generation system, see Pininfarina - Wind Tunnel ${ }^{14}$ for more technical details. While the test section is treated anechoically, Funke et al. ${ }^{15}$ demonstrated how reflections from the ceiling and side walls can interfere with the direct sound field and influence the measured directivity and the sound pressure level from one microphone position to the next. Due to the limited experimental campaign, no transfer functions have been measured to identify the acoustic characteristics of the test section nor any assessment of spectral broadening of CROR tones; one of the effects caused by the open jet wind tunnel shear layer has been performed, see examples in Campos ${ }^{16,17}$ and Guédel. ${ }^{18}$

\section{Propulsion system design}

Eurotech designed and developed the CROR engines for this project from specifications provided by Alenia Aermacchi. The design of the CROR used in this investigation features two planes of 12 blades. These are driven by a single electric motor and gear box, which produced identical speed of rotation for both blade planes. The electric motor/gear box selfnoise was found to be minor when compared to the CROR aerodynamic noise described in the following sections. One engine is instrumented with kulite pressure transducers on the front and rear blade planes: 12 on each row. The nacelle of this engine also houses slip ring connectors for instrumentation connections. Figures 3 and 4 show a photograph of the engine installed on the model in the pusher and tractor configuration, respectively.

The engine features variable blade pitch control, which can be adjusted to either a take-off or approach setting. The blade pitch settings were identified experimentally during an engine calibration to match the required performance as specified by the designs developed within

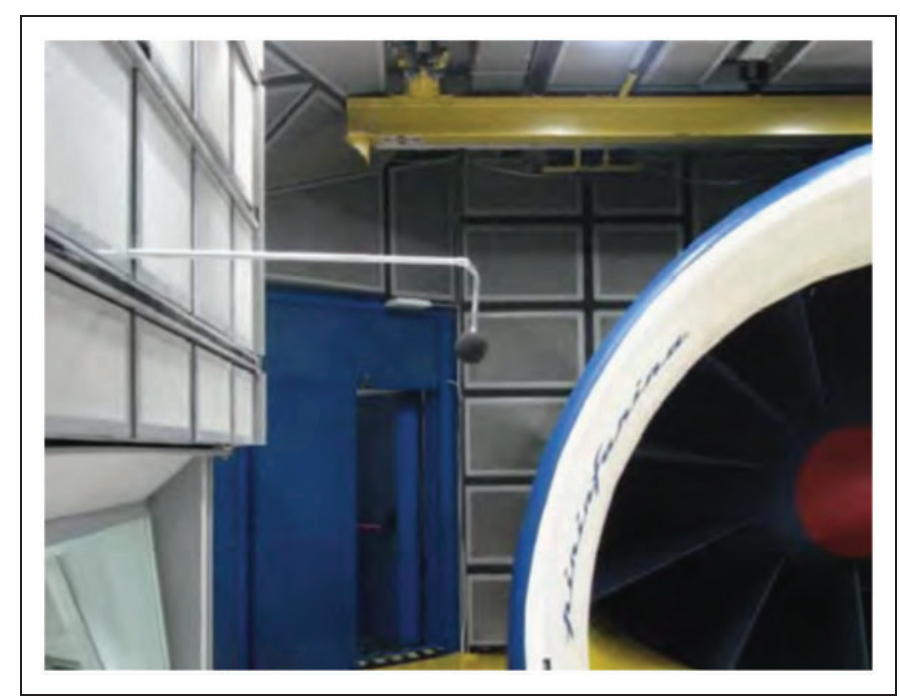

Figure 2. Out-of-flow microphone used for background measurements. 


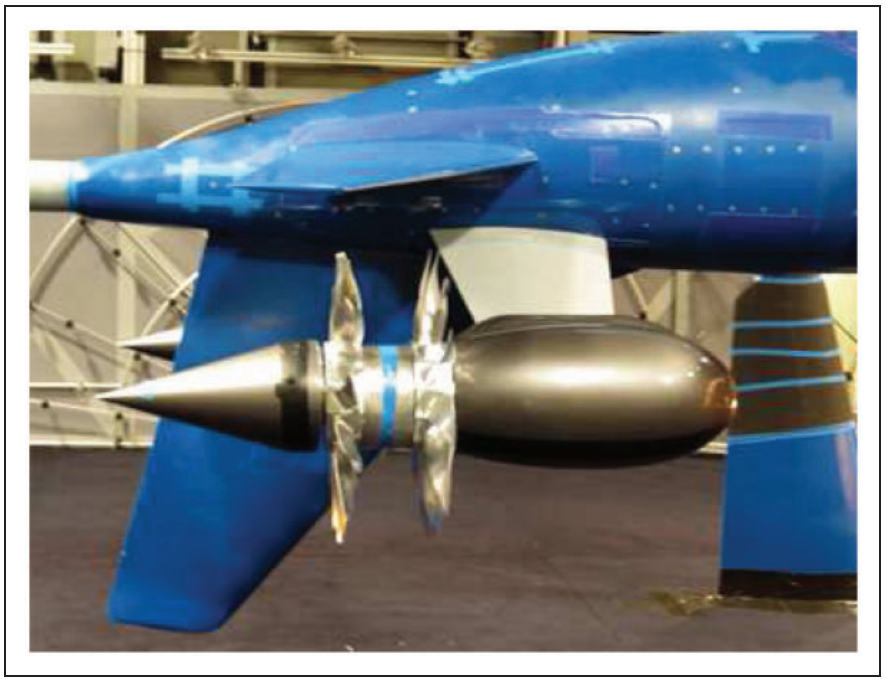

Figure 3. Installed CROR engine in pusher configuration.

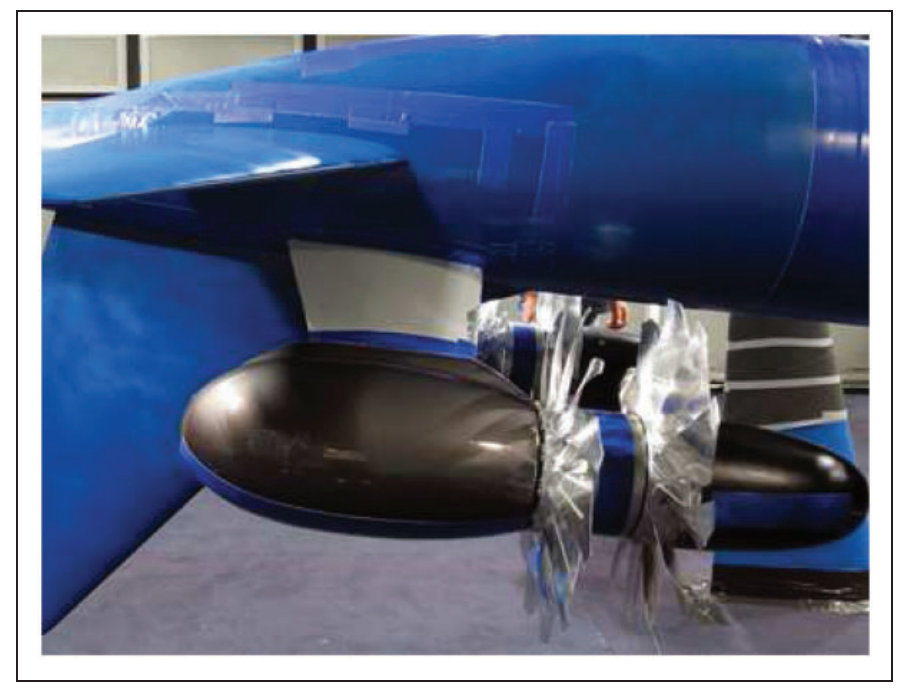

Figure 4. Installed CROR engine in tractor configuration.

the Clean Sky Green Regional Aircraft program. The engine calibration was carried out in a small wind tunnel. The engine was installed on a support pylon structure equipped with load cells at the bottom. A force balance (allowing for engine weight, pylon weight, pylon drag and engine torque) was implemented to evaluate and calibrate the CROR which was scaled to match the thrust for take-off and approach conditions Magnifico et al.; ${ }^{19}$ however, the values of the propeller thrust in all configurations are confidential. The blade hub assembly was designed to feature blade pitch control over a range of $60^{\circ}$. A simple rod and crank 


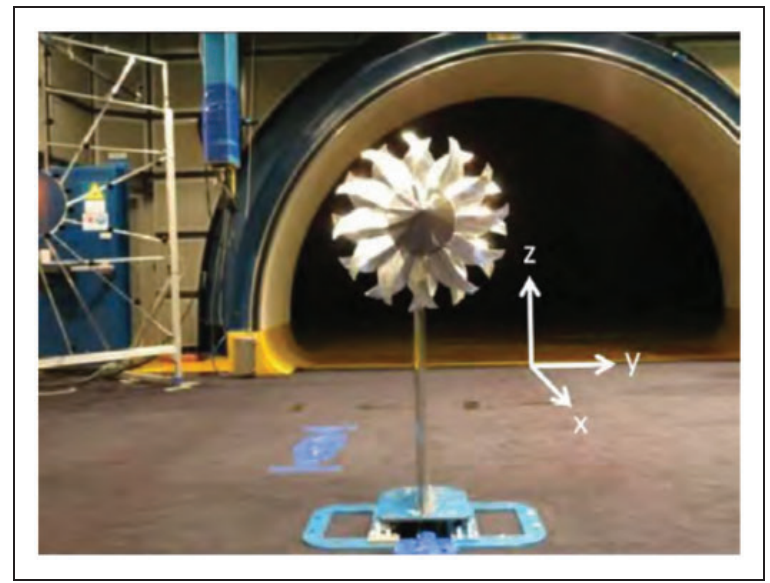

Figure 5. CROR in pusher configuration. The flow coincides with positive X-direction.

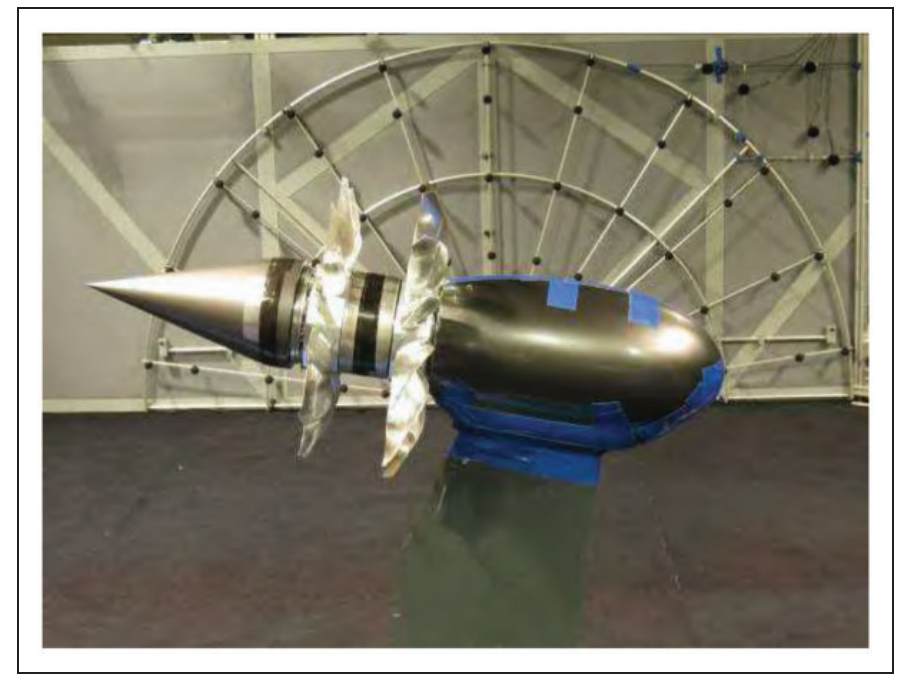

Figure 6. CROR in pusher configuration at non-zero angle of incidence, side view. The flow is from right to left.

system allowed for adjustable blade pitch control without the requirement for engine disassembly.

Figure 5 shows the upstream view of the 1/7th scale model of CROR installed on a pylon in pusher configuration and the origin of the coordinate system, which is referenced from the center width of the open jet nozzle exit plane. The side view of the CROR assembly installed on a pylon at a non-zero angle of incidence is depicted in Figure 6. It should be noted that this is not an "isolated" engine but rather, it is installed onto the same pylon design as is used to mount the engine onto the full model. Table 2 gives the front rotor center coordinates of 
Table 2. Front blade row center coordinates in $(\mathrm{mm})$.

\begin{tabular}{lrr}
\hline & Pusher & Tractor \\
\hline$X$ & 4483 & 3863 \\
$Y$ & -713 & -713 \\
$Z$ & 1029 & 1025 \\
\hline
\end{tabular}

both pusher and tractor configuration in the test section at zero angle of incidence with respect to the origin. The position of the open rotor (i.e. offset in Y-direction) was chosen deliberately in order to match the position of the engine when installed on the aircraft model, as shown in Figure 1, for the accompanying tests.

\section{Test configurations}

At each flow velocity of 20,24 , and $28 \mathrm{~m} / \mathrm{s}$, the pusher configuration was tested at an angle of incidence of $0^{\circ}, 6^{\circ}, 8^{\circ}$, and $10^{\circ}$ for take-off and $0^{\circ}, 4^{\circ}, 6^{\circ}$, and $8^{\circ}$ for approach. The flow velocities are associated with the model testing and obviously are not representative of a real aircraft at approach or take-off conditions. In total, 24 measurements have been performed for the pusher configuration. The tractor configuration in take-off setting was tested at the same flow velocities $(20,24$, and $28 \mathrm{~m} / \mathrm{s})$ for angles of incidence of $6^{\circ}, 8^{\circ}$, and $10^{\circ}$ resulting in nine measurements. Only three cases at $6^{\circ}$ for each flow velocity and two additional tests at angle of incidence of $4^{\circ}$ and $8^{\circ}$ for $24 \mathrm{~m} / \mathrm{s}$ were considered for tractor approach. In total, 14 tests were carried out for the tractor. The test matrix for the pylon installed CROR campaign is summarized in Table 3. According to the project input specifications, the engine speeds for both configurations were $2359 \mathrm{r} / \mathrm{min}$ in take-off setting and $2175 \mathrm{r} / \mathrm{min}$ for approach. The pusher and the tractor configurations are made using the same blades, blade pitch angles and electric motor to provide the required thrust levels (not available for public) at each test condition. It is important to note that aerodynamic features of the flow field are not always adequately reproduced when testing at small scale and that these flow details can be fundamental to the noise generation mechanisms.

The position of the engine in the wind tunnel test section is eccentric, hence a shear layer correction for off-axis sources in an open jet flow might be considered as an appropriate procedure. Morfey and Joseph ${ }^{20}$ proposed such a method for aircraft exhaust and airframe noise and concluded that the influence of source location on the shear layer amplitude corrections is generally modest (less than $0.5 \mathrm{~dB}$ ) for Mach numbers less than 0.5 (the Mach number is below 0.1 in this study) and for source radial locations: $r_{s} / a$ up to 0.5 , where $r_{s}$ is the source radius and $a$ is the jet radius $\left(r_{s} / a\right.$ is below 0.5 in this study). Given these considerations, the off-axis source in this work can instead be treated as an onaxis source and a shear layer correction method such as that proposed by Amiet ${ }^{21}$ could $^{2}$ instead be applied. Such a correction was carried out by Dobrzynski ${ }^{22}$ for a test set-up not dissimilar to ours. In that work, which had a low Mach number of 0.1 , similar to ours, negligible corrections of the order of magnitude of $1 \mathrm{~dB}$ were found to be required, apart from for one position at $150^{\circ}$, which is equivalent to our most downstream microphone no. 13, where a correction of $2 \mathrm{~dB}$ was needed. However, the application of such shear layer correction procedures to CROR emissions are still the subject of extensive study, are not 
Table 3. Test matrix for the pylon-installed CROR WENEMOR campaign.

\begin{tabular}{llllllll}
\hline Pusher take-off & $20(\mathrm{~m} / \mathrm{s})$ & $24(\mathrm{~m} / \mathrm{s})$ & $28(\mathrm{~m} / \mathrm{s})$ & Tractor take-off & $20(\mathrm{~m} / \mathrm{s})$ & $24(\mathrm{~m} / \mathrm{s})$ & $28(\mathrm{~m} / \mathrm{s})$ \\
\hline $0^{\circ}$ & $\checkmark$ & $\checkmark$ & $\checkmark$ & & $\checkmark$ & $\checkmark$ & $\checkmark$ \\
$6^{\circ}$ & $\checkmark$ & $\checkmark$ & $\checkmark$ & $\checkmark$ & $\checkmark$ & $\checkmark$ \\
$8^{\circ}$ & $\checkmark$ & $\checkmark$ & $\checkmark$ & $\checkmark$ & $\checkmark$ & $\checkmark$ \\
$I^{\circ}$ & $\checkmark$ & $\checkmark$ & $\checkmark$ & Tractor approach & & & \\
Pusher approach & & & & & $\checkmark$ & \\
$0^{\circ}$ & $\checkmark$ & $\checkmark$ & $\checkmark$ & $\checkmark$ & $\checkmark$ & $\checkmark$ \\
$4^{\circ}$ & $\checkmark$ & $\checkmark$ & $\checkmark$ & & $\checkmark$ & \\
$6^{\circ}$ & $\checkmark$ & $\checkmark$ & $\checkmark$ & $\checkmark$ & & \\
$8^{\circ}$ & $\checkmark$ & $\checkmark$ & $\checkmark$ & & & \\
\hline
\end{tabular}

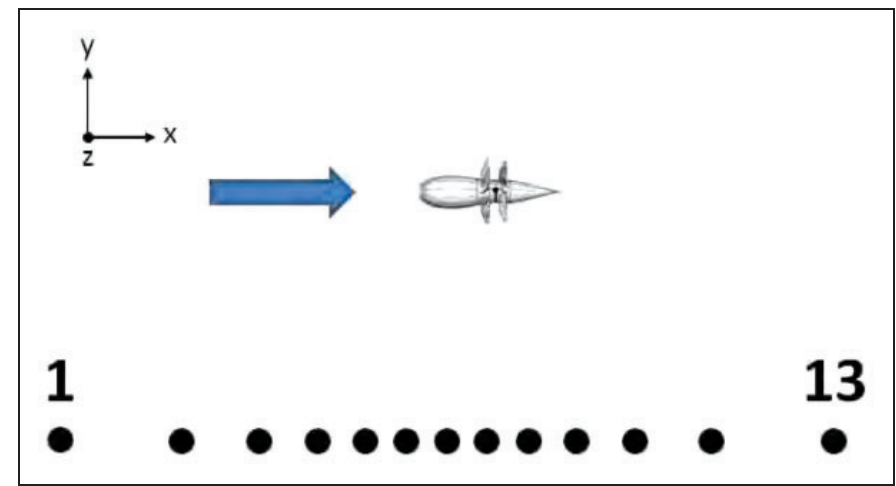

Figure 7. Far field linear array layout.

straightforward and may not even be applicable for the more complicated sound fields generated by a CROR source. For example, Funke et al. ${ }^{15}$ performed acoustic measurements on a CROR with a shear layer correction for a wind tunnel Mach number ranging from 0.2 to 0.3 and the authors obtained meaningful results only for a small range of emission angles. Since the presumed amplitude corrections are minor and existing shear layer correction methods for CROR emissions are uncertain, the results of this study are presented without any shear layer corrections. This is all the more reasonable as the focus of the study is on the relative comparison of acoustic emissions between pusher and tractor configurations, where the shear layer effects on the noise characteristics are effectively cancelled out.

In this paper, a far field linear array of 13 microphones is deployed for the principal sound measurements at a sampling rate of $32,768 \mathrm{~Hz}$ for $10 \mathrm{~s}$ durations. Although a significantly higher sampling rate would be necessary to obtain the full scale audible spectrum on a $1 / 7$ th scale model, the sampling rate used in the testing was limited by the wind tunnel system hardware. The layout of this array is shown in Figure 7 and sensor coordinates are provided by Table 4 . The wind tunnel facility was equipped with three microphone phased arrays with the intention of identifying noise sources; however, a recent paper by Horváth et al. ${ }^{23}$ 
Table 4. Linear far field array sensor positions in (m).

\begin{tabular}{lrrrrrrrrrrrrr}
\hline Sensor I & 2 & 3 & 4 & 5 & 6 & 7 & 8 & 9 & 10 & 11 & 12 & 13 \\
\hline$X$ & -0.125 & 1.195 & 2.030 & 2.675 & 3.195 & 3.640 & 4.075 & 4.510 & 4.955 & 5.475 & 6.120 & 6.955 & 8.275 \\
$Y$ & -3.335 & -3.335 & -3.335 & -3.335 & -3.335 & -3.335 & -3.335 & -3.335 & -3.335 & -3.335 & -3.335 & -3.335 & -3.335 \\
$Z$ & 2.680 & 2.680 & 2.680 & 2.680 & 2.680 & 2.680 & 2.680 & 2.680 & 2.680 & 2.680 & 2.680 & 2.680 & 2.680 \\
\hline
\end{tabular}

demonstrates that the application of conventional phased array techniques (beamforming) to open rotor noise emissions can yield misleading results of the source locations. For this reason no beamforming maps are presented here, but the data will be re-examined at a later stage.

\section{Acoustic analysis}

In general, the noise signature of CRORs contains rotor-alone tones of the front and the aft rotor at the blade passing frequency (BPF), the harmonics of these and their interaction tones, which are sums of the harmonics of each BPF as demonstrated by Lewy. ${ }^{24}$ Because the forward and aft rotors have the same number of blades $(B)$ and the same rotational speed $(N)$, the frequency of the rotor-alone tones and the frequency of the associated interaction tones cannot be distinguished from each other. The tone frequencies are expressed by equation (1)

$$
f=n B N
$$

where $n=n_{1}+n_{2}$ and $n_{1}, n_{2}$ are integers associated with front and rear rotor, respectively. For instance, the frequency of interaction tone $n_{1}=1, n_{2}=1$ is the same as the harmonic of the front rotor-alone tone $n_{1}=2, n_{2}=0$ and the harmonic of the rear rotor-alone tone $n_{1}=0, n_{2}=2$. The work of Hanson ${ }^{25}$ shows that due to the Bessel functions of the 0th order, even sound tones tend to dominate the isolated CROR noise emissions, which radiate efficiently upstream and downstream of the engine.

It is useful to look at a sample spectrum to get an idea of what the noise signature of the CROR under investigation is. For certification reasons, data were analyzed using the National Instruments Labview Sound and Vibration toolkit. A custom software tool was created to calculate a narrow band analysis up to $10 \mathrm{kHz}$ with a frequency resolution of $1 \mathrm{~Hz}$, $50 \%$ overlap, Hanning window and number of averages of 20 . Figure 8 shows the spectrum obtained by microphone 8 of the linear array (see Figure 7) from a measurement of the pusher configuration during take-off at $28 \mathrm{~m} / \mathrm{s}$ and an angle of incidence of $10^{\circ}$ and the background noise spectrum at the same flow velocity (background noise data not available with a fine frequency resolution). The major vertical grid lines represent the even multiples of the BPF. The tone at $2 \times \mathrm{BPF}$ tends to dominate the spectrum in this particular test, which agrees with the theory of Hanson, ${ }^{25}$ although the CROR noise is clearly influenced by the presence of the pylon. Due to the collapse of the rotor-alone and interaction tones, it is rather impossible to assess the individual contribution of each pylon-rotor noise, rotor-rotor interaction noise and rotor-alone noise from the tone directivity patterns in the far field. In the case of unequal blade count of the two rotors in the pusher configuration, the experience showed that the pylon-rotor interaction affects primarily the front rotor-alone tones and 


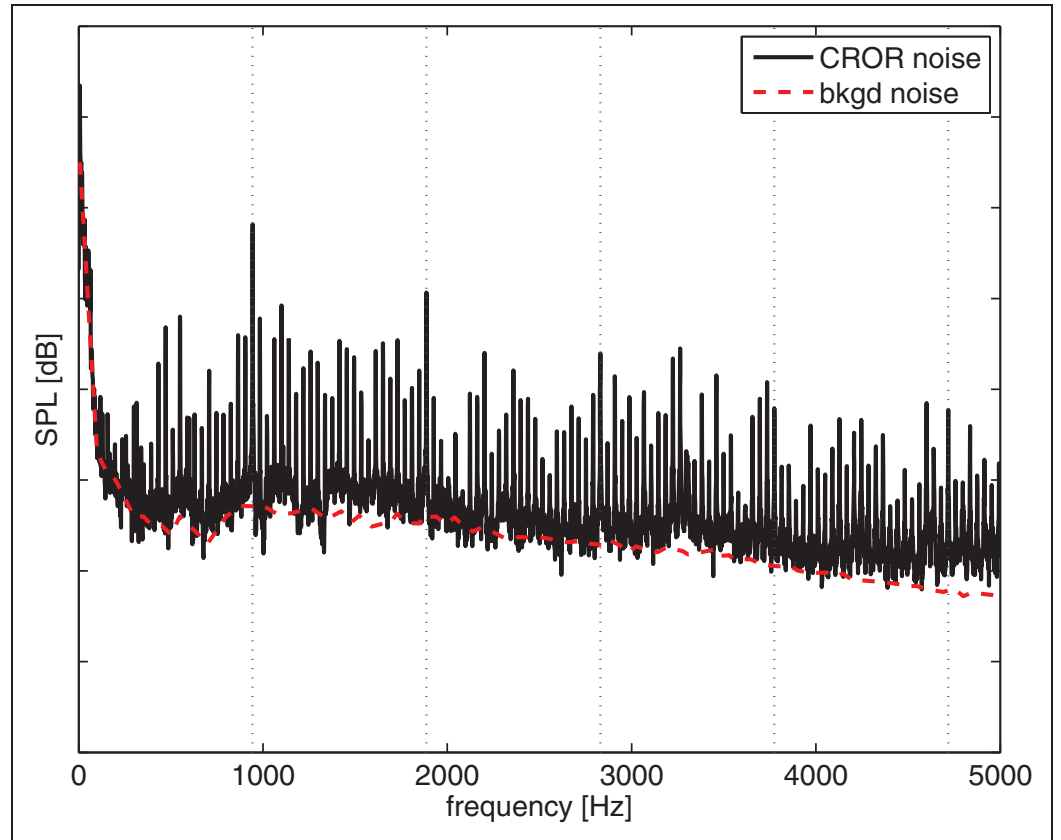

Figure 8. Spectrum at mic 8 for pusher at $28 \mathrm{~m} / \mathrm{s}, 10^{\circ}$ angle of incidence, take-off, with background noise at the same flow velocity. The major vertical grid lines represent the even multiples of BPF.

causes higher noise levels, see example in Ricouard et al., ${ }^{5}$ and the same effect can be expected for the present setup. Moreover, analytic work of Brouwer ${ }^{26}$ suggests that the rotor-alone tones radiate efficiently from the blade tip regions, while the interaction tone sources can be found over the whole blade length. A detailed near field investigation would be required to verify these hypotheses.

The plot of Figure 8 shows an example of a test point, where the spectrum is rich with the tone multiples of the shaft order, i.e. a frequency step of $39.32 \mathrm{~Hz}$ is vivid. Magnitudes of some engine tone multiples are high, but these are not analyzed as only BPF harmonics (rotor-alone tones and interaction tones) are theoretically associated with CROR noise. This observation might suggest that, at relatively low levels of thrust, every blade contributes individually to the overall noise signature. A plausible explanation could be found in manufacturing inaccuracies of the blades or even the impact of the spiral bevel gears on the noise signals. An additional explanation comes from the fact that the pusher configuration is strongly subject to the downstream wake from the pylon, which would generate tones of shaft order. Moreover, the thin blade profiles are susceptible to vibration, and displacement amplitudes of the blade tips (in various modes of both blades and blade disks) can influence significantly the low level signals of acoustic pressure; $1 / 3$ octave band analysis and OASPL are not detailed here as the CROR acoustic energy could be significantly masked or increased by the tone multiples of the engine speed; an example can be found in the extreme case of Figure 8 for the higher frequencies. A possible coalescence of modal frequency with a frequency associated with acoustic phenomena is beyond the scope of this paper. 


\section{Pusher}

The pusher test campaign was slightly more extensive than the tractor acoustic measurements. At each flow velocity of 20,24 , and $28 \mathrm{~m} / \mathrm{s}$, the pusher configuration was tested at an angle of incidence of $0^{\circ}, 6^{\circ}, 8^{\circ}$, and $10^{\circ}$ for take-off (2359 RPM) and $0^{\circ}, 4^{\circ}, 6^{\circ}$, and $8^{\circ}$ for approach $(2175 \mathrm{r} / \mathrm{min})$. Results which cannot be directly compared with the tractor configuration are highlighted in this section, while the rest of the comparative findings are presented in the next section. Note that to aid easy comparison between plots for the entire paper, the spacing between the vertical ticks is $10 \mathrm{~dB}$ and the lower and upper limits of the sound pressure level axes are the same in all directivity plots.

Figure 9 depicts the tone directivity trends of the CROR tones up to $4 \times$ BPF for three various flow velocities at zero angle of incidence as measured on the linear array. It is difficult to observe some obvious dependency of the tone levels of directivity plots with increasing flow speed. Associated theoretical approaches can also lead to different conclusions. As example, for a given rotation speed, increasing the axial Mach number actually leads to a decrease of the thrust because the blade relative flow incidence decreases (according to the velocity triangle), hence a reduction of the steady loading noise (the other noise

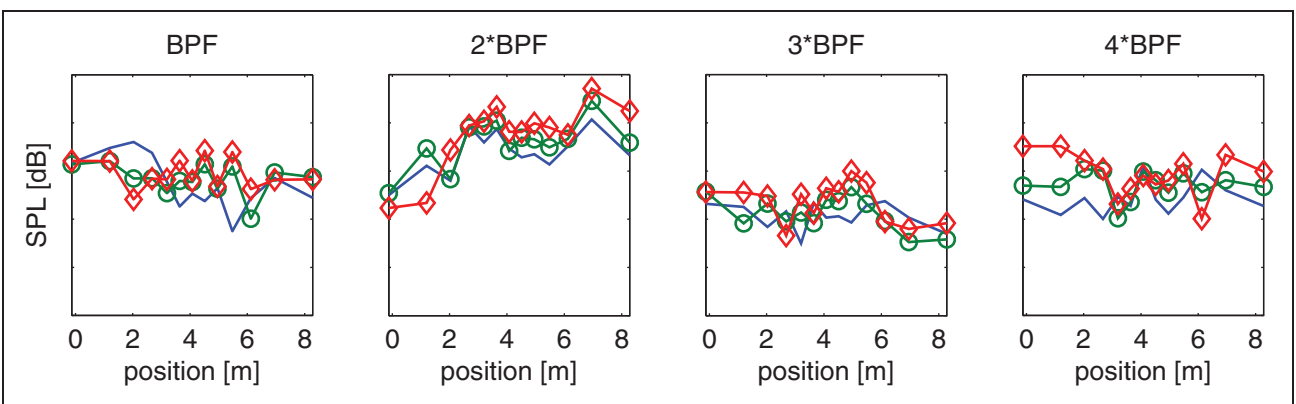

Figure 9. Pusher, take-off, zero angle of incidence: tone directivity on linear array at various flow speeds: $-20 \mathrm{~m} / \mathrm{s},{ }^{\circ} 24 \mathrm{~m} / \mathrm{s}, \diamond 28 \mathrm{~m} / \mathrm{s}$. Distance between vertical ticks is $10 \mathrm{~dB}$.

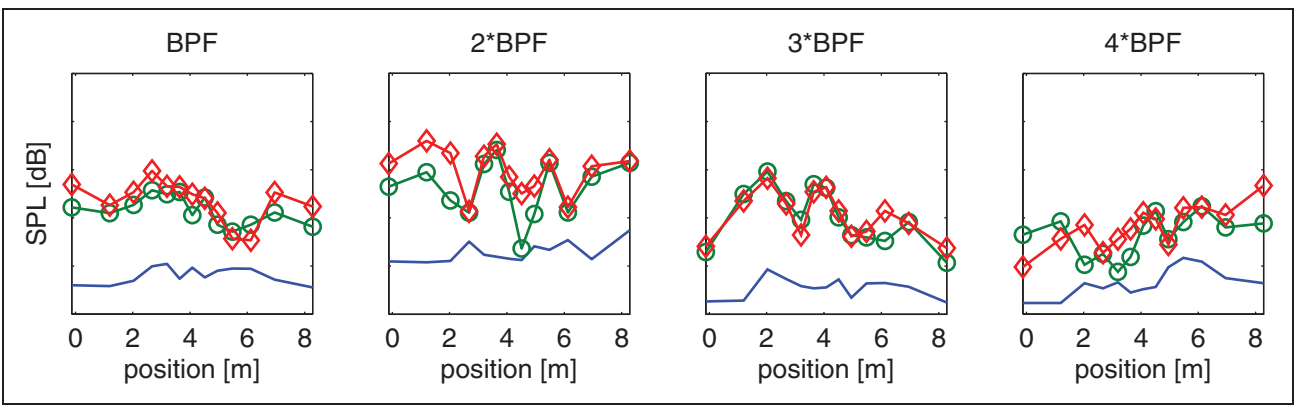

Figure 10. Pusher, approach, zero angle of incidence: tone directivity on linear array at various flow speeds: $-20 \mathrm{~m} / \mathrm{s},{ }^{\circ} 24 \mathrm{~m} / \mathrm{s}, \diamond 28 \mathrm{~m} / \mathrm{s}$. Distance between vertical ticks is $10 \mathrm{~dB}$. 


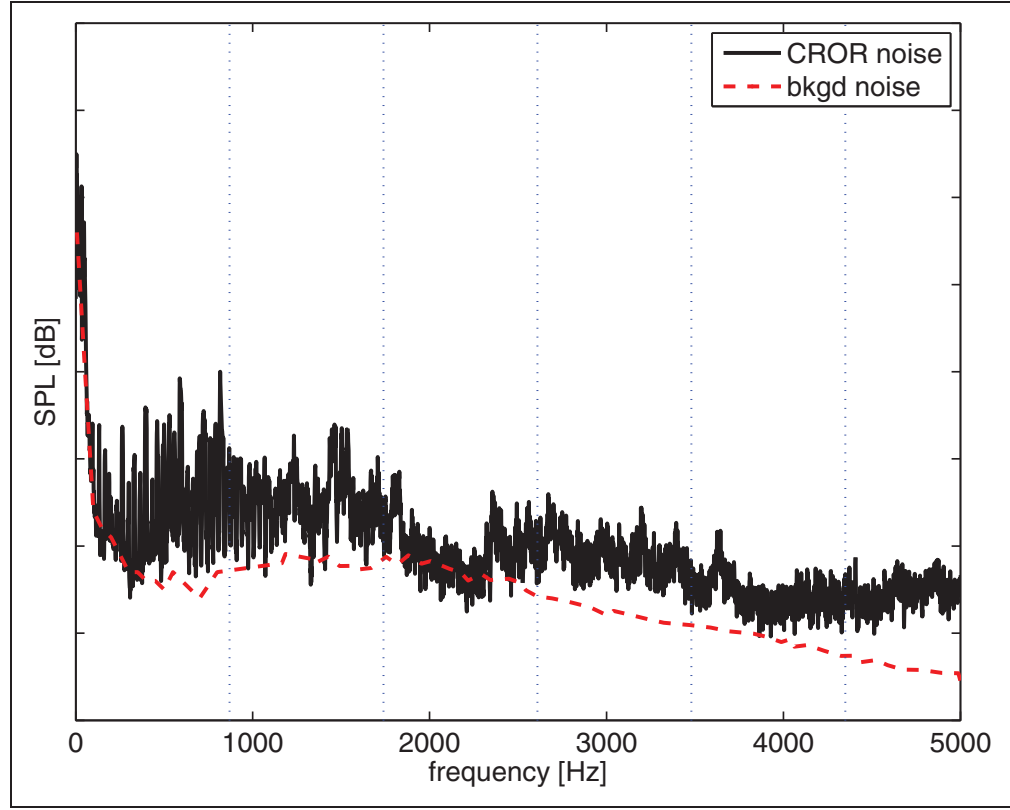

Figure II. Spectrum at mic 8 for pusher in approach at $20 \mathrm{~m} / \mathrm{s}$ and zero angle of incidence with background noise at the same flow velocity.

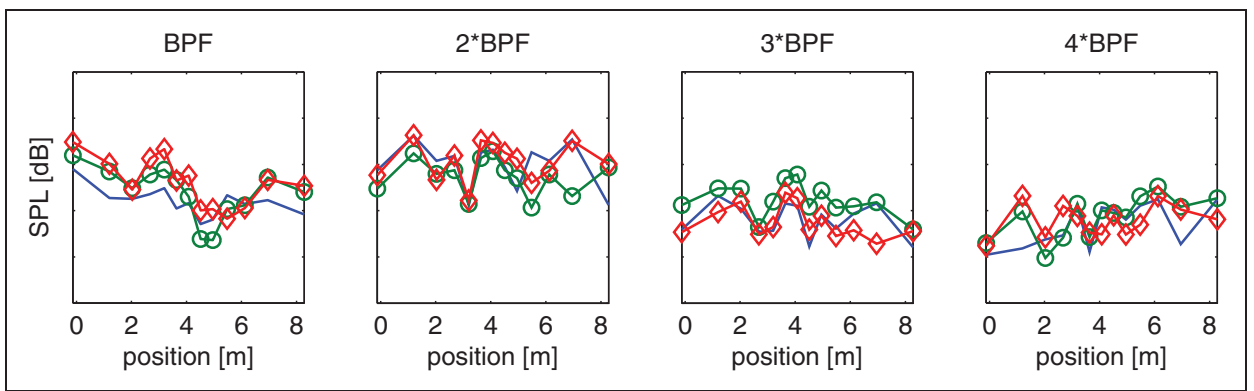

Figure 12. Pusher, approach, angle of incidence of $8^{\circ}$ : tone directivity on linear array at various flow speeds: $-20 \mathrm{~m} / \mathrm{s},{ }^{\circ} 24 \mathrm{~m} / \mathrm{s}, \diamond 28 \mathrm{~m} / \mathrm{s}$. Distance between vertical ticks is $10 \mathrm{~dB}$.

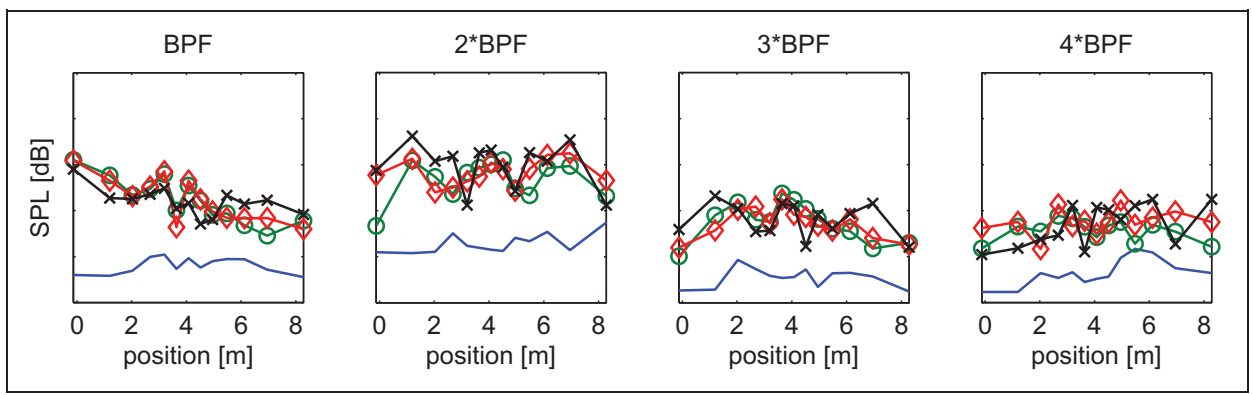

Figure 13. Pusher, approach, $20 \mathrm{~m} / \mathrm{s}$ : tone directivity on linear array at various angles of incidence: $0^{\circ}, 4^{\circ}, \diamond 6^{\circ}, \times 8^{\circ}$. Distance between vertical ticks is $10 \mathrm{~dB}$. 
sources remain unchanged in subsonic configurations). However, a higher inflow Mach number would induce a deeper pylon wake and stronger blade load fluctuations that would indeed increase tone levels corresponding to the fluctuation frequencies. The overall trends show the efficient on-axis radiation with the tones at $2 \times$ BPF dominating downstream of the CROR. Figure 10 depicts the same situations for approach configuration.

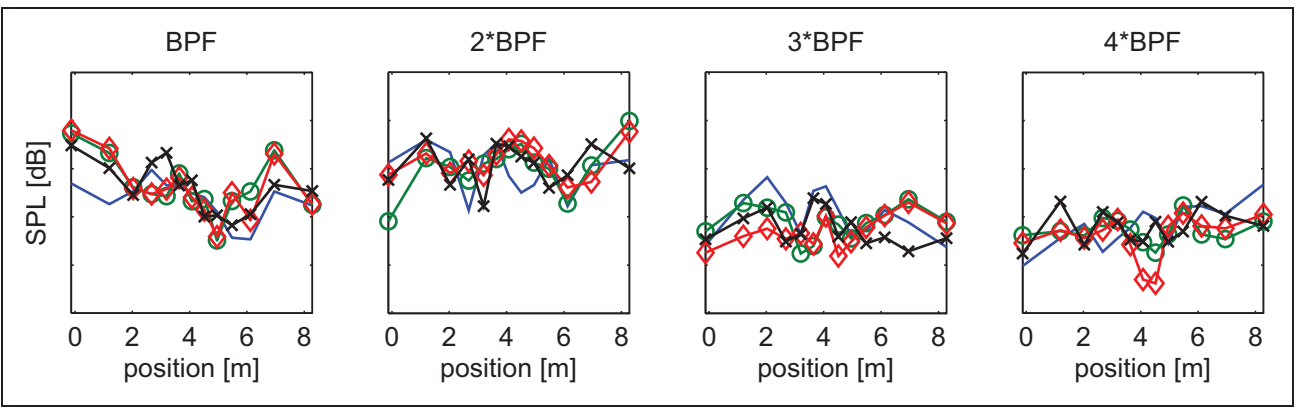

Figure 14. Pusher, approach, $28 \mathrm{~m} / \mathrm{s}$ : tone directivity on linear array at various angles of incidence: $0^{\circ}, 4^{\circ}, \diamond 6^{\circ}, \times 8^{\circ}$. Distance between vertical ticks is $10 \mathrm{~dB}$.

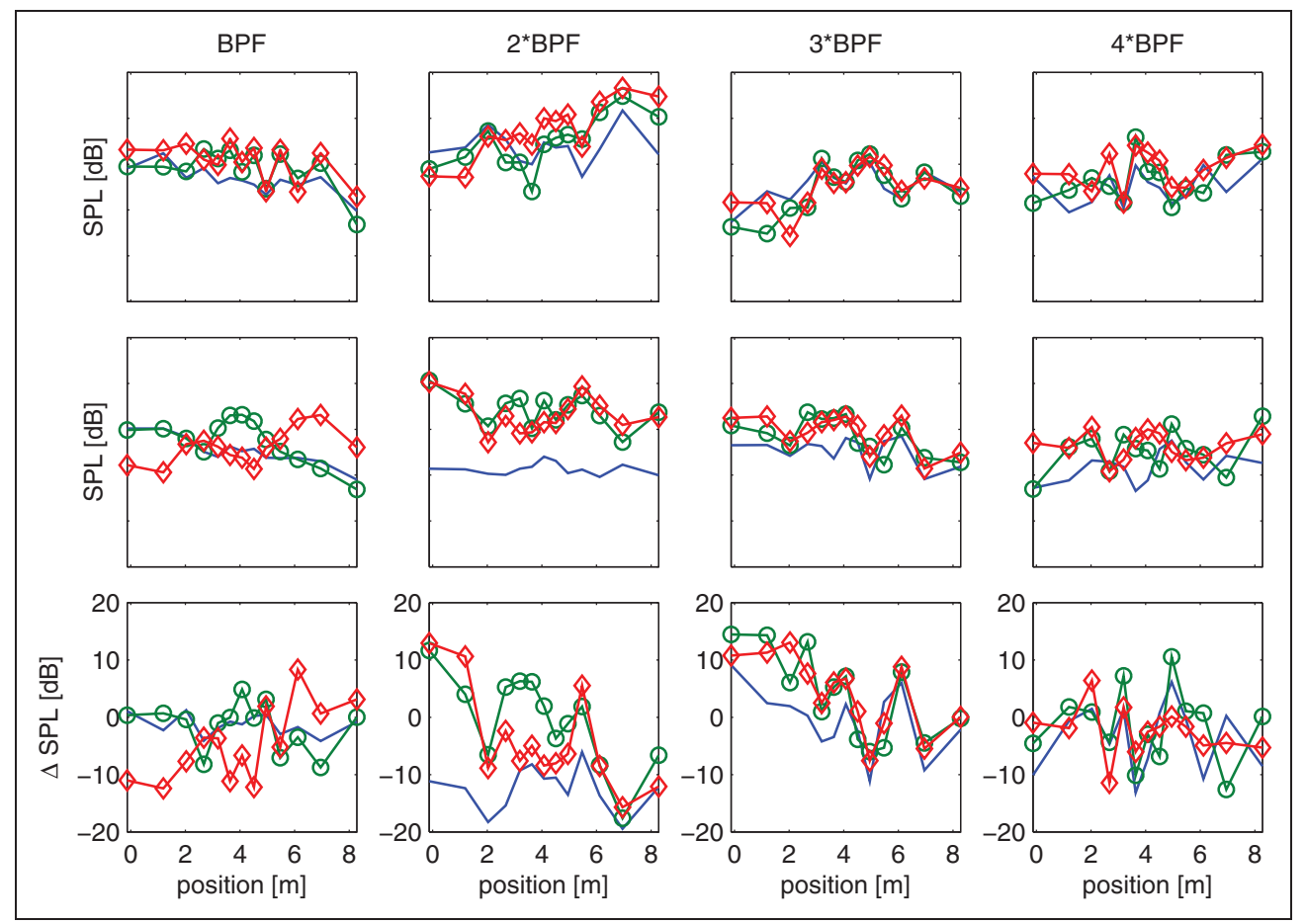

Figure 15. Pusher (top row) and tractor (middle row), take-off, angle of incidence of $6^{\circ}$ : tone directivity on linear array at various flow speeds: $-20 \mathrm{~m} / \mathrm{s},{ }^{\circ} 24 \mathrm{~m} / \mathrm{s}, \diamond 28 \mathrm{~m} / \mathrm{s}$. Distance between vertical ticks is $10 \mathrm{~dB}$. The bottom row is a relative comparison between pusher and tractor. 
Figure 11 shows that there are no distinct CROR tones at $20 \mathrm{~m} / \mathrm{s}$ for zero angle of incidence, which explains the low-sound pressure levels of Figure 10 at this flow velocity. Hence, it is not possible to investigate the tone directivities at $20 \mathrm{~m} / \mathrm{s}$ for zero angle of incidence and it is highlighted that the $n \times$ BPF directivity patterns at this condition are not representative of tonal directivities. As expected, both Figures 9 and 10 reveal that the pusher performs quieter at approach than at take-off. Tone directivity trends on the linear array at various flow speeds for angle of incidence of $8^{\circ}$ in approach pusher setting are found in Figure 12. The sound pressure levels at $20 \mathrm{~m} / \mathrm{s}$ are now quantitatively the same as the data for other flow velocities in contrast to zero angle of incidence. The increased angle of incidence for the pusher at approach caused higher noise levels at BPF and $2 \times$ BPF tones. Figures 13 and 14 depict the tone directivity trends on the linear array at various angles of incidence for $20 \mathrm{~m} / \mathrm{s}$ and $28 \mathrm{~m} / \mathrm{s}$, respectively, in approach. In both situations BPF and $2 \times \mathrm{BPF}$ tones radiate more efficiently than other harmonics. For the BPF tone at higher angles of incidence, the maximum of the directivity plot tends to be upstream of the CROR.

\section{Comparison between the pusher and the tractor}

The tractor configuration is a viable alternative to the historical pusher configuration, which has been researched more intensively. While in the pusher configuration, the

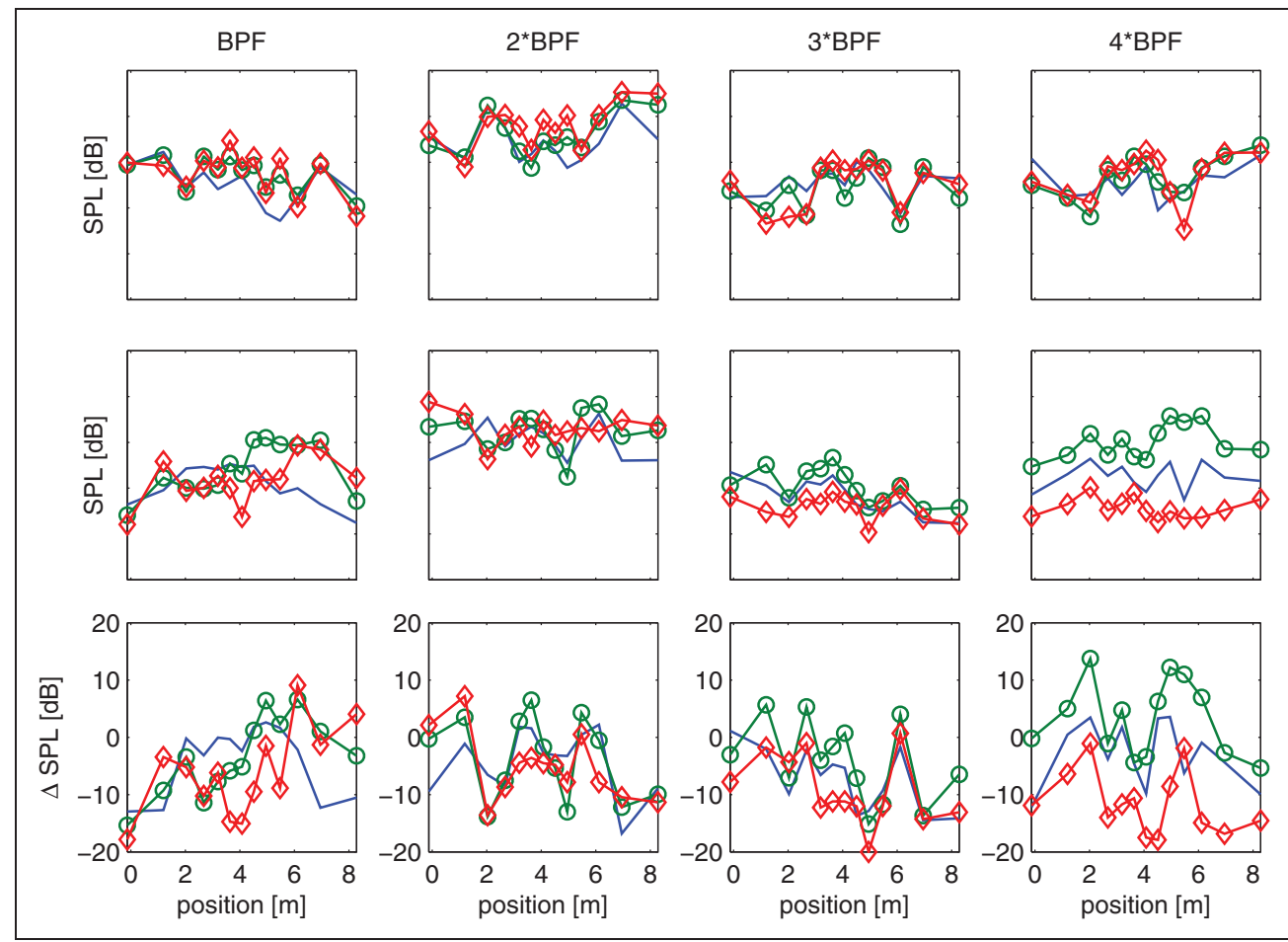

Figure 16. Pusher (top row) and tractor (middle row), take-off, angle of incidence of $8^{\circ}$ : tone directivity on linear array at various flow speeds: $-20 \mathrm{~m} / \mathrm{s},{ }^{\circ} 24 \mathrm{~m} / \mathrm{s}, \diamond 28 \mathrm{~m} / \mathrm{s}$. Distance between vertical ticks is $10 \mathrm{~dB}$. The bottom row is a relative comparison between pusher and tractor. 
interaction between the pylon wake and the front rotor blades is an important contribution to noise due to the once per revolution unsteady loading on each front blade. In the tractor configuration on the other hand, the pylon being installed downstream of the rear rotor, the additional noise sources by comparison to a true isolated configuration arise as (i) the rear rotor wakes impinge on the pylon and (ii) the pylon potential effects induce once per revolution loading fluctuations on the rear rotor blades (and less importantly on the front rotor blades). In both pusher and tractor configurations, it can be noted that the subsequent tonal noise increase occurs at the BPF harmonics. By assuming that the pylon wake-front rotor interaction of the pusher is stronger than the potential effect of the tractor pylon, the front BPF increase can be more dramatic on the former configuration. The hypothesis is supported by observations in Shivashankara et al. ${ }^{27}$ Magliozzi et al. ${ }^{28}$

The tractor configuration was tested at flow velocities of 20,24 , and $28 \mathrm{~m} / \mathrm{s}$ and angles of incidence of $6^{\circ}, 8^{\circ}$, and $10^{\circ}$ for take-off $(2359 \mathrm{r} / \mathrm{min})$. There were acoustic measurements of tractor for the approach setting $(2175 \mathrm{r} / \mathrm{min})$ at $6^{\circ}$ for each flow velocity and two additional tests at angle of incidence of $4^{\circ}$ and $8^{\circ}$ for $24 \mathrm{~m} / \mathrm{s}$ only. The results can be directly compared to the pusher configuration under the same flow velocities and angles of incidence.

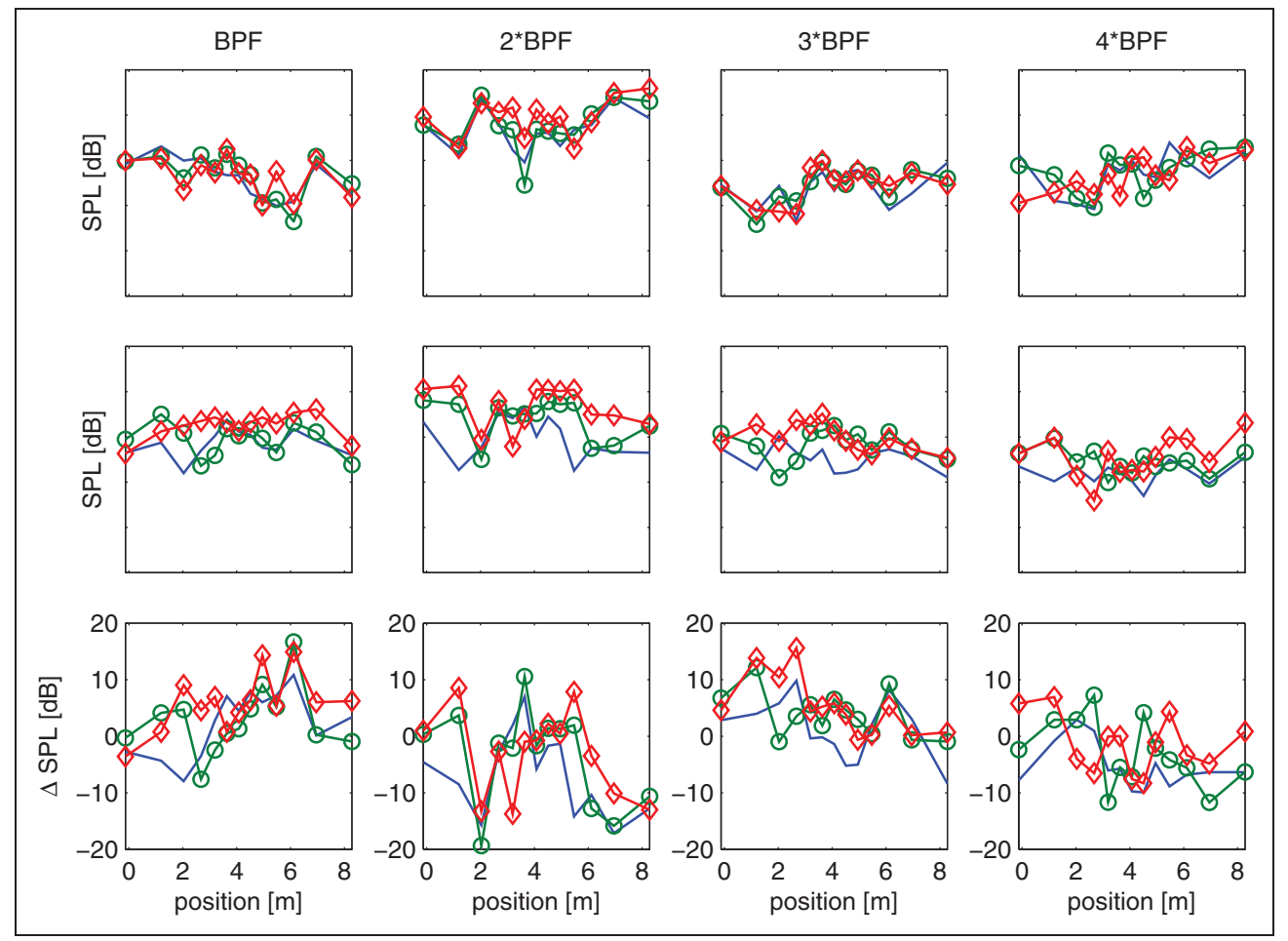

Figure 17. Pusher (top row) and tractor (middle row), take-off, angle of incidence of $10^{\circ}$ : tone directivity on linear array at various flow speeds: $-20 \mathrm{~m} / \mathrm{s},{ }^{\circ} 24 \mathrm{~m} / \mathrm{s}, \diamond 28 \mathrm{~m} / \mathrm{s}$. Distance between vertical ticks is $10 \mathrm{~dB}$. The bottom row is a relative comparison between pusher and tractor. 


\section{Take-off}

Figure 15 shows the pusher (top row) and the tractor (middle row) at take-off, respectively, at an angle of incidence of $6^{\circ}$ for various flow speeds. At the dominant frequency of $2 \times$ BPF and higher flow velocities (i.e. 24 and $28 \mathrm{~m} / \mathrm{s}$ ), the pusher seems to radiate more acoustic energy downstream of the CROR, while the tractor radiates efficiently upstream of the CROR. This is obvious from the bottom row of Figure 15 depicting a relative comparison between the pusher and the tractor, where $\Delta$ SPL above 0 means the tractor is louder than the pusher. Situation is different at the fundamental BPF and flow velocity of $28 \mathrm{~m} / \mathrm{s}$, when the tractor is quieter upstream of the engine and louder than the pusher downstream of the engine, while the tractor performs significantly worse upstream of the engine at $3 \times \mathrm{BPF}$. In general, the variety in all plots and the obscure characteristic of tractor at $20 \mathrm{~m} / \mathrm{s}$ (distinct tones available, but not in the vicinity of $2 \times$ BPF) demonstrate the complexity of CROR acoustic performance. However, the efficient on-axis acoustic radiation can be seen, to a certain degree, at most BPF tones.

At angle of incidence of $8^{\circ}$, the pusher tends to be the loudest at frequency of $2 \times \mathrm{BPF}$ as shown in the top row of Figure 16. The tractor also radiates efficiently at this frequency and moreover, there is a considerable increase of SPL at $4 \times \mathrm{BPF}$ for $24 \mathrm{~m} / \mathrm{s}$ (middle row of Figure 16). In both $\mathrm{BPF}$ and $2 \times \mathrm{BPF}$, the tractor performs quieter than the pusher at the

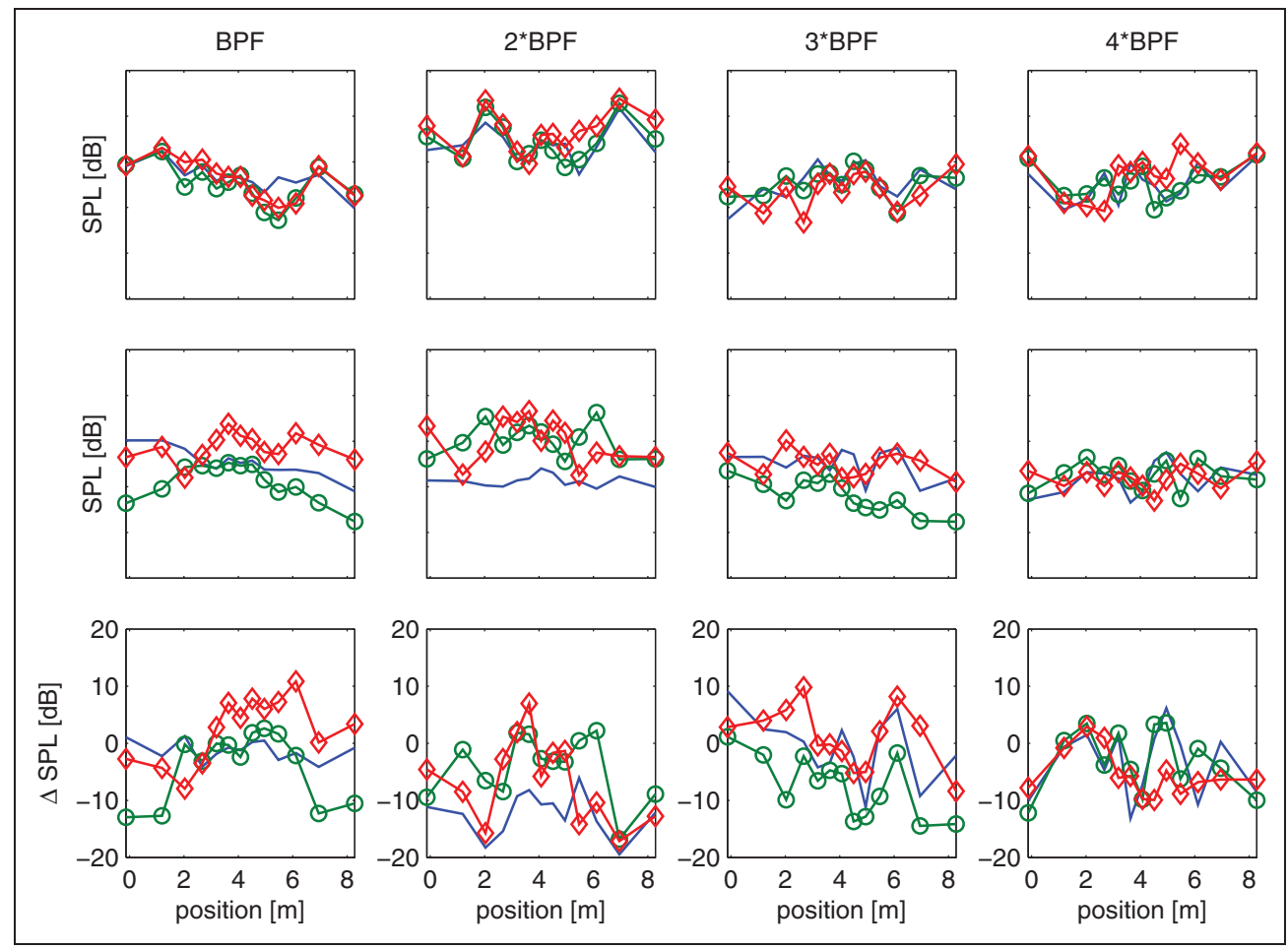

Figure 18. Pusher (top row) and tractor (middle row), take-off, $20 \mathrm{~m} / \mathrm{s}$ : tone directivity on linear array at various angles of incidence: $-6^{\circ},{ }^{\circ} 8^{\circ}, \diamond 10^{\circ}$. Distance between vertical ticks is $10 \mathrm{~dB}$. The bottom row is a relative comparison between pusher and tractor. 
majority of the measuring points (see bottom row of Figure 16), especially at $28 \mathrm{~m} / \mathrm{s}$. At angle of incidence of $10^{\circ}$, the bottom row of Figure 17 reveals that the tractor is mostly louder at BPF and evidently quieter at $2 \times \mathrm{BPF}$ downstream of the engine.

Figure 18 shows the tone directivity trends of pusher and tractor at take-off for various angles of incidence as measured at flow velocity of $20 \mathrm{~m} / \mathrm{s}$. For the pusher configuration (Figure 18, top row), the plots are similar with a small data scatter, relatively independent of various angles of incidence and have distinct tones at $2 \times \mathrm{BPF}$. The tractor is quieter at this frequency as shown in the bottom row of Figure 18. The dominance of $2 \times \mathrm{BPF}$ tones can be found repeatedly in the pusher take-off setting at higher flow velocities of $24 \mathrm{~m} / \mathrm{s}$ and $28 \mathrm{~m} / \mathrm{s}$ as depicted in Figures 19 and 20. The acoustic signature of the tractor configuration at take-off varies significantly with the change in angle of incidence and $2 \times$ BPF tones seem to be suppressed at majority of the microphones when compared to the pusher (see bottom row in Figures 19 and 20). Strikingly, there is a drop of acoustic energy for the tractor at $3 \times$ BPF and $4 \times \mathrm{BPF}$ at angle of incidence of $8^{\circ}$ and flow velocity of $28 \mathrm{~m} / \mathrm{s}$ (Figure 20, middle row), caused by low distinct tones in the vicinity of $3 \times \mathrm{BPF}$ and $4 \times \mathrm{BPF}$ and the reason remains unclear.

\section{Approach}

In all approach configurations tested, the frequencies BPF and $2 \times \mathrm{BPF}$ tend to dominate the spectra; the former with an efficient upstream radiation. Figure 21 depicts the pusher and

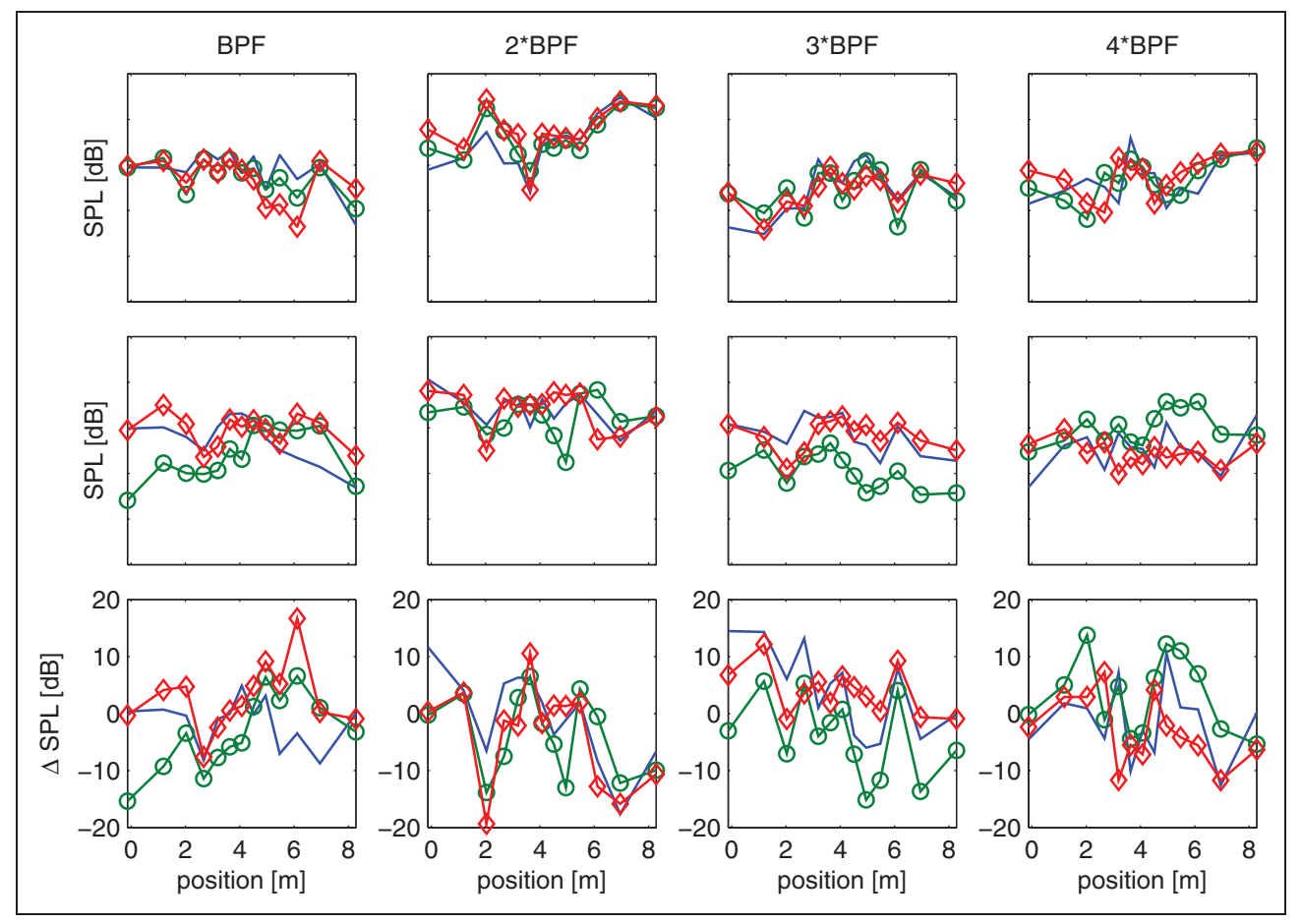

Figure 19. Pusher (top row) and tractor (middle row), take-off, $24 \mathrm{~m} / \mathrm{s}$ : tone directivity on linear array at various angles of incidence: $-6^{\circ},{ }^{\circ} 8^{\circ}, \diamond 10^{\circ}$. Distance between vertical ticks is $10 \mathrm{~dB}$. The bottom row is a relative comparison between pusher and tractor. 
tractor configuration in approach at flow velocity of $24 \mathrm{~m} / \mathrm{s}$ for all angles of incidence. The tractor configuration is found to be dramatically quieter than the pusher at BPF and $2 \times$ BPF. According to the theory, this effect might benefit from the lower inflow disturbances due to the absence of upstream pylon wake. However, there were other distinct tones (not at nBPF) suggesting that the acoustic energy could be dispersed from the rotor harmonics and the underlying mechanism is not clear at the moment. Figure 22 shows the pusher and tractor in approach at an angle of incidence of $6^{\circ}$ for all flow velocities. The trends confirm a quieter behavior of the tractor at the dominant frequencies BPF and $2 \times \mathrm{BPF}$.

\section{Conclusion}

The paper summarizes the basic findings of an experimental campaign of the pylon-installed CROR, which was tested within the WENEMOR project. The engine features the same rotational speed and equal blade number of both front and aft rotors, which means that the $\mathrm{BPF}$ of rotor-alone tones and the frequency of relevant interaction tones cannot be distinguished. The tone directivity plots, obtained by a far field linear array of 13 microphones, are presented for both pusher and tractor configurations at various angles of incidence and flow velocities up to $4 \times \mathrm{BPF}$. The results show the efficient on-axis acoustic radiation at all $\mathrm{BPF}$

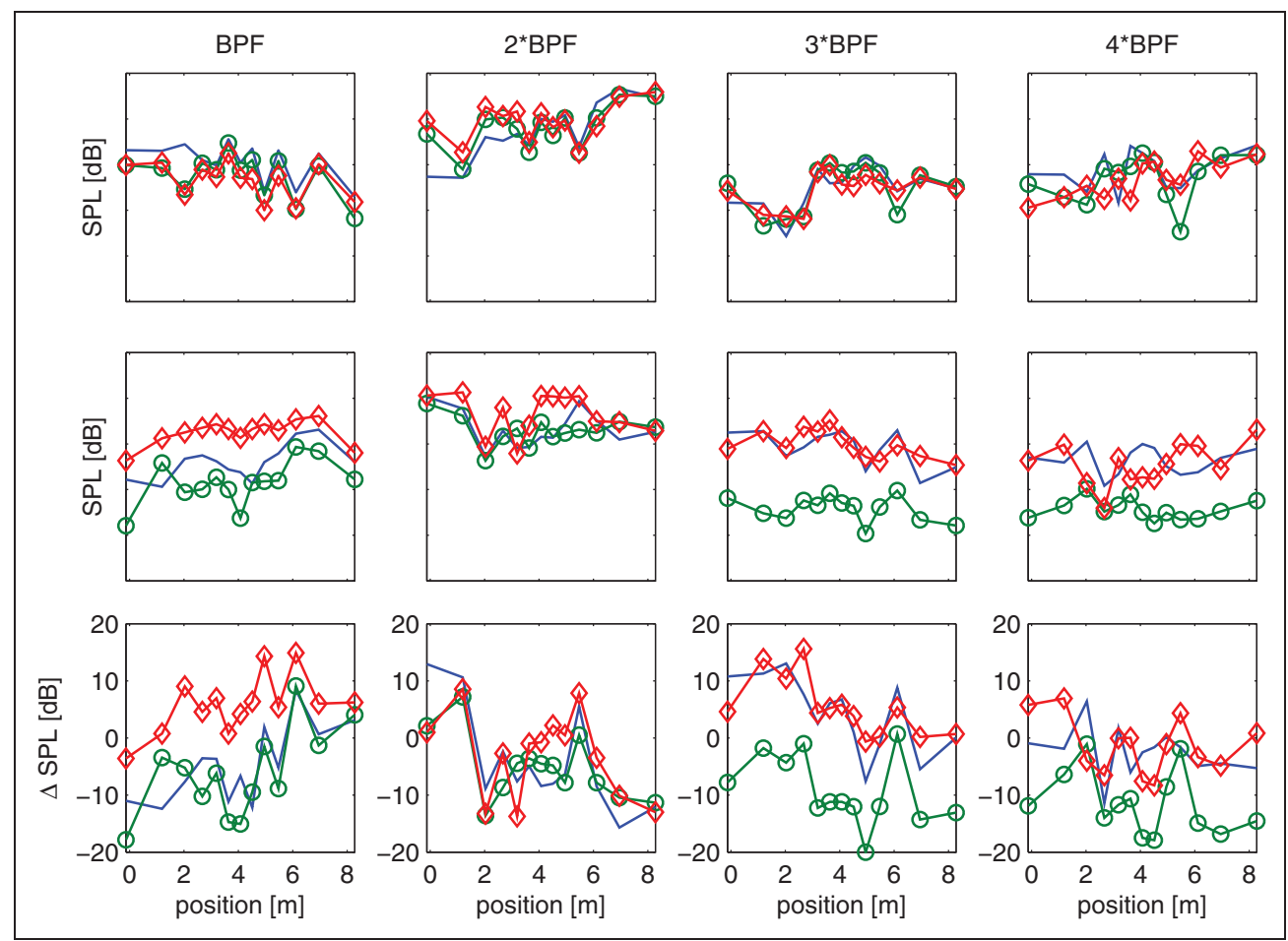

Figure 20. Pusher (top row) and tractor (middle row), take-off, $28 \mathrm{~m} / \mathrm{s}$ : tone directivity on linear array at various angles of incidence: $-6^{\circ},{ }^{\circ} 8^{\circ}, \diamond 10^{\circ}$. Distance between vertical ticks is $10 \mathrm{~dB}$. The bottom row is a relative comparison between pusher and tractor. 


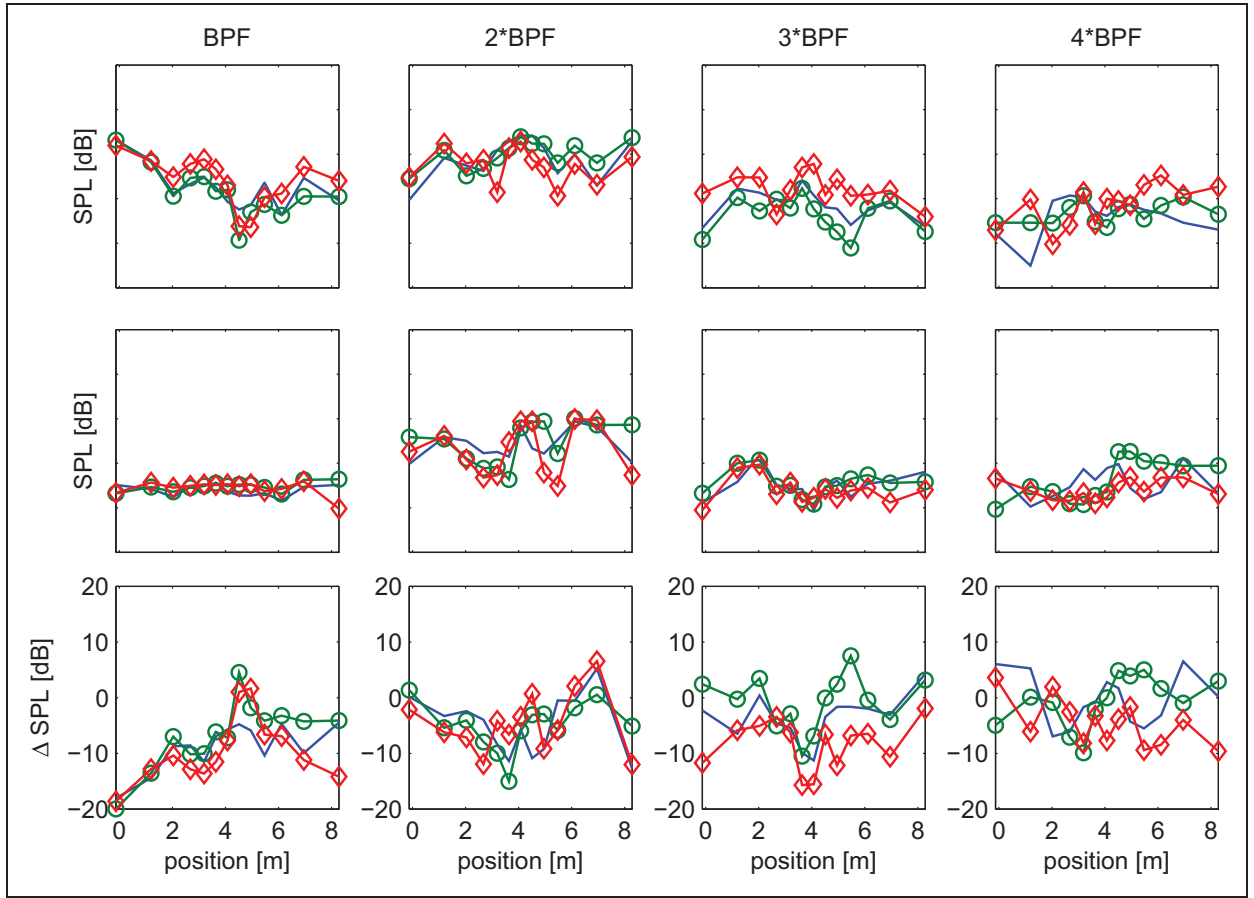

Figure 2I. Pusher (top row) and tractor (middle row), approach, $24 \mathrm{~m} / \mathrm{s}$ : tone directivity on linear array at various angles of incidence: $-4^{\circ},{ }^{\circ} 6^{\circ}, \diamond 8^{\circ}$. Distance between vertical ticks is $10 \mathrm{~dB}$. The bottom row is a relative comparison between pusher and tractor.

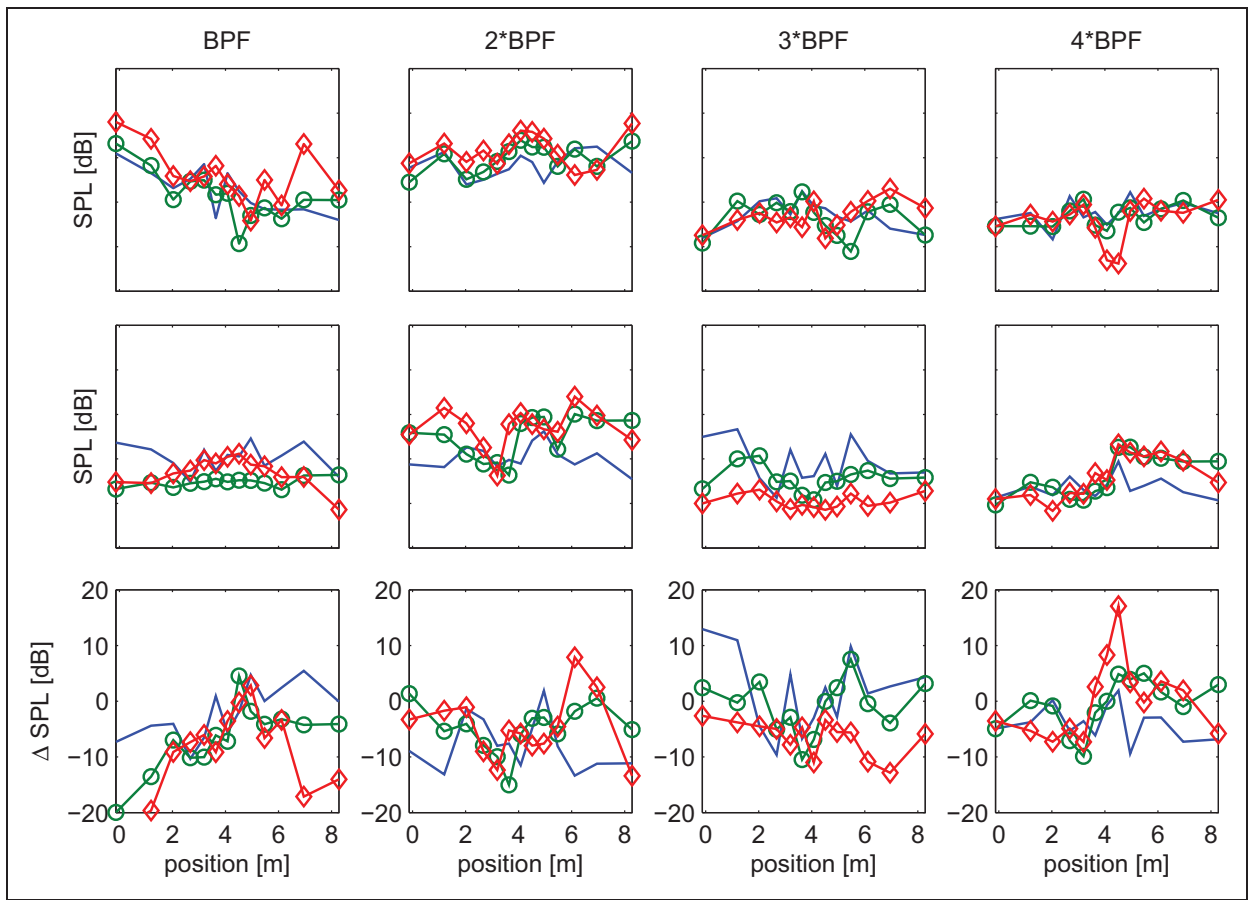

Figure 22. Pusher (top row) and tractor (middle row), approach, angle of incidence of $6^{\circ}$ : tone directivity on linear array at various flow speeds: $-20 \mathrm{~m} / \mathrm{s},{ }^{\circ} 24 \mathrm{~m} / \mathrm{s}, \diamond 28 \mathrm{~m} / \mathrm{s}$. Distance between vertical ticks is $10 \mathrm{~dB}$. The bottom row is a relative comparison between pusher and tractor. 
tones with the CROR tone at $2 \times \mathrm{BPF}$ dominating in the vast majority of the tests. The comparisons of the acoustic emissions between the pusher and the tractor tested under the same flow velocities and angles of incidence favor slightly the tractor configuration at $2 \times \mathrm{BPF}$. However, the acoustic signature of CROR was complicated and no general trends of the directivity plots as function of the increasing flow velocity and the angles of incidence were observed for both pusher and tractor configurations.

\section{Acknowledgement}

The authors wish to thank and acknowledge the work of the WENEMOR consortium partners for the design, manufacture and testing of the wind tunnel model. Also, M. Massimiliano Di Giulio, Topic Manager, Alenia Aermacchi, Naples, Italy. The authors would like to dedicate this work to the late Professor John Fitzpatrick, a great mentor and friend.

\section{Declaration of conflicting interests}

The author(s) declared no potential conflicts of interest with respect to the research, authorship, and/or publication of this article.

\section{Funding}

Grant agreement no: 278419. European Union FP7 Clean Sky Joint Technology Initiative.

\section{References}

1. Blandeau VP, Joseph PF, Kingan MJ, et al. Broadband noise predictions from uninstalled contrarotating open rotors. International Journal of Aeroacoustics 2013; 12: 245-282.

2. Peters A and Spakovszky ZS. Rotor interaction noise in counter-rotating propfan propulsion systems. J Turbomach 2011; 134: 1-12.

3. Zachariadis A, Hall C and Parry AB. Contrarotating open rotor operation for improved aerodynamics and noise at takeoff. $J$ Turbomach 2013; 135: 1-10.

4. Schnell R, Yin J, Voss C, et al. Assessment and optimization of the aerodynamic and acoustic characteristics of a counter rotating open rotor. J Turbomach 2012; 134: 1-15.

5. Ricouard J, Julliard E, Omaïs M, et al. Installation effects on contra-rotating open rotor noise. In: 16th AIAA/CEAS aeroacoustics conference, 7-9 June 2010, Stockholm, Sweden, 2010.

6. Elliott DM. Initial investigation of the acoustics of a counter-rotating open rotor model with historical baseline blades in a low-speed wind tunnel. In: 32nd AIAA aeroacoustics conference, Portland, Oregon, USA, 5-8 June 2011.

7. Czech MJ and Thomas RH. Open rotor installed aeroacoustic testing with conventional and unconventional airframes. In: 19th AIAA/CEAS aeroacoustics conference, 27-29 May 2013, Berlin, Germany, 2013.

8. Zante DEV. The NASA environmentally responsible aviation project/general electric open rotor test campaign. In: 51st AIAA aerospace sciences meeting including the new horizons forum and aerospace exposition, 7-10 January, Grapevine, Texas, USA.

9. Stephens DB and Envia E.Acoustic shielding for a model scale counter-rotation open rotor.In: 17th AIAA/CEAS aeroacoustics conference (32nd AIAA aeroacoustics conference) Portland, Oregon, USA, 5-8 June 2011.

10. Fernando R and Leroux M. Open-rotor low speed aero-acoustics: wind tunnel characterization of an advanced blade design in isolated and installed configurations. In: 20th AIAA/CEAS aeroacoustics conference, Atlanta, GA, USA, 16-20 June 2014. 
11. Bennett GJ, Kennedy J, Eret P, et al. WENEMOR: wind tunnel tests for the evaluation of the installation effects of noise emissions of an open rotor advanced regional aircraft. In: 19th AIAA/ CEAS aeroacoustics conference, Berlin, Germany, 27-29 May 2013.

12. Parry AB and Vianello S.A. project study of open rotor noise'. International J Aeroacoust 2012; 11 : 247-258.

13. Sanders L, Mincu DC, Denis W, et al. A coupling of computational methods for CROR installation effects. In: 20th AIAA/CEAS aeroacoustics conference, 16-20 June, Atlanta, GA, USA.

14. Pininfarina - Wind Tunnel (n.d.), www.pininfarina.com/en/services/wind_tunnel (accessed 21 March 2016).

15. Funke S, Kim L and Siller H. Acoustic measurements of a contra-rotating open rotor in an open jet wind-tunnel. Int J Aeroacoust 2012; 11: 197-212.

16. Campos LMBC. The spectral broadening of sound by turbulent shear layers. Part 1. The transmission of sound through turbulent shear layers. J Fluid Mech 1978a; 89: 723-749.

17. Campos LMBC. The spectral broadening of sound by turbulent shear layers. Part 2. The spectral broadening of sound and aircraft noise. J Fluid Mech 1978b; 89: 751-783.

18. Guédel A. Scattering of an acoustic field by a free jet shear layer. J Sound Vib 1985; 100: 285-304.

19. Magnifico M, Arena G and Amoroso F. Characteristic propeller curves and performance of engine simulator system. Technical report, WENEMOR Technical Deliverable: D2.5-009, 2012.

20. Morfey $\mathrm{C}$ and Joseph P. Shear layer refraction corrections for off-axis sources in a jet flow. $J$ Sound Vib 2001; 239: 819-848.

21. Amiet R. 'Refraction of sound by a shear layer'. Journal of Sound and Vibration 1978; 58: 467-482.

22. Dobrzynski W. Shear-layer correction after Amiet under consideration of additional temperature gradient. Working diagrams for correction of signals. Technical report, NASA TM-77741, 1984.

23. Horváth C, Envia E and Podboy GG. Limitations of phased array beamforming in open rotor noise source imaging. AIAA $J$ 2014; 52: 1810-1817.

24. Lewy S. Semi-empirical prediction of tone noise due to counter-rotating open rotors. In: Proceedings of 20th international congress on acoustics, ICA 2010, 23-27 August 2010, Sydney, Australia.

25. Hanson DB. Noise of counter-rotation propellers. J Aircraft 1985; 22: 609-617.

26. Brouwer HH. Analytic description of the noise radiation from single- and contra-rotating propellers. Technical report, NLR-TP-2011-295, 2011.

27. Shivashankara BN, Johnson DP and Cuthbertson RD. Installation effects on counter rotating propeller noise. In: 13th AIAA aeroacoustics conference, Tallahassee, FL, 22-24 October 1990.

28. Magliozzi B, Brown P and Parzych D. Acoustic test and analysis of a counterrotating prop-fan model. Technical report, NASA CR 179590, 1987.

\section{Appendix}

\section{Notation}

$B$ number of blades

$f$ CROR tone

$N$ rotational speed

$n$ integer 